\title{
ДОСЛІДЖЕННЯ РЕГУЛЯТОРА КОНЦЕНТРАЦЇ̈ РІДКОГО ПОГЛИНАЧА ЕНЕРГОБЛОКУ АЕС
}

Research of regulator of liquid absorber concentration of NPP

Беглов К.В. ${ }^{1}$, Волошкіна О.О. ${ }^{1}$, Плахотнюк O.A. ${ }^{1}$ (Beglov K.V., Voloshkina O.A., Plakhotnuk A.A.)

${ }^{1}$ Одеський національний політехнічний університет

Copyright (C) 2014 by author and the journal "Automation technological and business - processes". This work is licensed under the Creative Commons Attribution International License (CC BY). http://creativecommons.org/licenses/by/4.0/

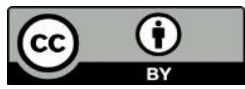

ONAFT

Open Access

DOI: $10.15673 /$

\begin{abstract}
Аннотация
Дослідження регулятора концентрації рідкого поглинача енергоблоку АЕС. У теперішній час актуальним завданням с управління енергоблоком АЕC в маневреному режимі. При маневруванні потужність енергоблоку можна змінювати за допомогою зміни концентрації ізотопу бору ${ }^{10} B$ в теплоносії першого контуру. Ізотоп бору ${ }^{10} \mathrm{~B}$ с поглиначем нейтронів. Найбільш зручним способом зміни концентрації бору $\mathrm{\epsilon}$ зміна концентрації борної кислоти. В даному випадку борна кислота виконус роль рідкого поглинача нейтронів, що дозволяс безперервно управляти процесом поділу ядерного палива. Особливістю першого контуру 3 погляду управління концентрацією рідким поглиначем с різні статичні й динамічні характеристики при введенні і виведенні борної кислоти, тобто при нанесенні керуючого впливу 3 різними знаками. Таким чином, виникас задача синтезу регулятора концентрації борної кислоти для нелінійного об'скта. У роботі наводиться обгрунтування структури та параметрів регулятора потужності енергоблоку при регулюванні за допомогою рідкого поглинача. У процесі розрахунків було визначено, що оптимальним с регулятор з ПІ-законом управління, який налаштований на об’скт з мінімальним коефіціснтом передачі та максимальною постійною часу.
\end{abstract}

\section{Abstract}

Research of regulator of liquid absorber concentration of NPP. Currently, an urgent task is to control nuclear power units in maneuvering mode. When maneuvering power unit can be changed by changing the concentration of boron isotope ${ }^{10} \mathrm{~B}$ in the primary coolant. Boron isotope ${ }^{10} \mathrm{~B}$ is a neutron absorber. The most convenient way of changing the boron concentration is to change the concentration of boric acid. In this case, boric acid is a liquid neutron absorber, which allows continuous control the fission process of nuclear fuel. A feature of the first circuit in terms of controlling the concentration of liquid absorber is different static and dynamic characteristics in the input and output of boric acid, that is, when applied to the control action with different signs. Thus, there is the problem of synthesizing control the concentration of boric acid to the non-linear object. The articles provides a rationale for the structure and parameters of the NPP control of the regulation with a liquid absorbent. During the calculations it was determined that the optimum control is the PI-regulator, which is set to the object with the minimum transmission ratio and maximum constant time.

Ключові слова

Концентрація борної кислоти, аср, регулятор. 
Вступ

В теперішній час виникла задача плавного регулювання потужності енергоблоків АЕС. Одним 3 методів регулювання є зміна концентрації борної кислоти (БК) в теплоносії першого контуру АЕС. Але як об’єкт регулювання концентрація БК має різні статичні та динамічні властивості при нанесенні керуючого впливу 3 різними знаками. [1]

Мета роботи

Метою роботи є синтез та дослідження автоматизованої системи регулювання борної кислоти в теплоносії першого контуру для об'єкта зі змінними статичними та динамічними властивостями.

Викладення основного матеріалу

На АЕС з реакторами типу ВВЕР важливим завданням є контроль деяких параметрів теплоносія. Одним 3 основних контрольованих параметрів $є$ вміст БК ізотопу ${ }^{10} \mathrm{~B}$ у технологічних розчинах енергоблоків.

Процес зміни концентрації борної кислоти в теплоносії першого контуру називається борним регулюванням (БР). Борне регулювання, згідно ГОСТ 24693-81, застосовується для:

- компенсації повільних змін реактивності, пов'язаних 3 вигоранням ядерного палива, отруєнням ${ }^{135} \mathrm{Xe}{ }^{149} \mathrm{Sm}$, розігрівом-розхолоджування першого контуру із заданими швидкостями і змінами потужності реактора;

- забезпечення переходу з будь-якого стану нормальної експлуатації в підкритичний стан і підтримання цього стану при робочій температурі теплоносія;

- створення і підтримки в першому контурі концентрації борної кислоти, необхідної для безпечного проведення перевантаження реактора і ремонтних робіт;

- компенсації протікань теплоносія 3 першого контуру до значень, що не вимагають включення систем аварійного введення бору.

При необхідності проведення БР в колектор ПН подається розчин з бака з концентрованою БК або $з$ бака 3 чистим конденсатом (знесоленої водою).

Оцінку своїх дій по БР оперативний персонал здійснює, як правило, по зміні рівня потужності, аксіального офсету і значенням коефіцієнтів нерівномірності енерговиділення [2].

В роботі [3] розглянута залежність концентрації в АЗ при введені БК та при введені чистого конденсату в теплоносій першого контуру. Криві розгону по вказаним каналам представленні на 1 рисунку.
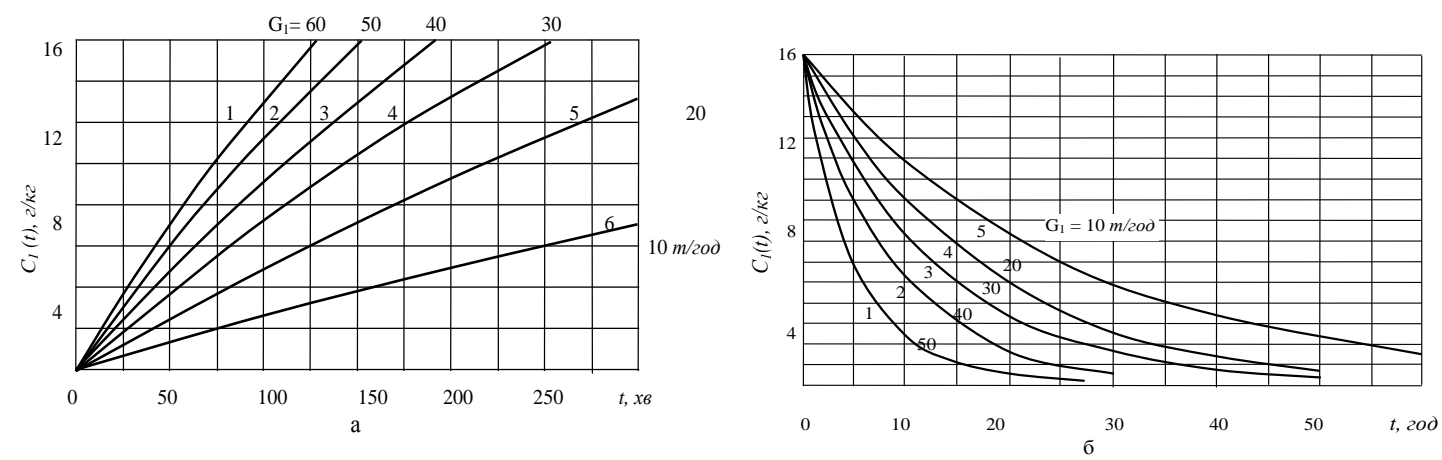

Рис. 1. Зміна концентрації борної кислоти в теплоносії у випадку підживлення концентрованою борною кислотою (a) і чистим конденсатом (б)

Для рисунка 1 (a):

1. Зміна концентрації борної кислоти в теплоносії у випадку підживлення концентрованою борною кислотою при номінальній витраті борної кислоти $\Delta G_{b o r}=60 \mathrm{~m} / 2$ од;

2. Зміна концентрації борної кислоти в теплоносії у випадку підживлення концентрованою борною кислотою при номінальній витраті борної кислоти $\Delta G_{b o r}=50 \mathrm{~m} /$ год;

3. Зміна концентрації борної кислоти в теплоносії у випадку підживлення концентрованою борною кислотою при номінальній витраті борної кислоти $\Delta G_{b o r}=40 \mathrm{~m} / 2$ од;

4. Зміна концентрації борної кислоти в теплоносії у випадку підживлення концентрованою борною кислотою при номінальній витраті борної кислоти $\Delta G_{b o r}=30 \mathrm{~m} /$ год;

5. Зміна концентрації борної кислоти в теплоносії у випадку підживлення концентрованою борною кислотою при номінальній витраті борної кислоти $\Delta G_{b o r}=20 \mathrm{~m} /$ год; 
6. Зміна концентрації борної кислоти в теплоносії у випадку підживлення концентрованою борною кислотою при номінальній витраті борної кислоти $\Delta G_{b o r}=10 \mathrm{~m} / 20 \partial$.

Для рисунка 1 (б):

1. Зміна концентрації борної кислоти в теплоносії у випадку підживлення чистим конденсатом при номінальній витраті чистого конденсату $\Delta G_{b o r}=50 \mathrm{~m} / 2$ од;

2. Зміна концентрації борної кислоти в теплоносії у випадку підживлення чистим конденсатом при номінальній витраті чистого конденсату $\Delta G_{b o r}=40 \mathrm{~m} / 2$ од;

3. Зміна концентрації борної кислоти в теплоносії у випадку підживлення чистим конденсатом при номінальній витраті чистого конденсату $\Delta G_{b o r}=30 \mathrm{~m} /$ год;

4. Зміна концентрації борної кислоти в теплоносії у випадку підживлення чистим конденсатом при номінальній витраті чистого конденсату $\Delta G_{b o r}=20 \mathrm{~m} / 2$ од;

5. Зміна концентрації борної кислоти в теплоносії у випадку підживлення чистим конденсатом при номінальній витраті чистого конденсату $\Delta G_{b o r}=10 \mathrm{~m} /$ год;

Для моделювання дані залежності були ідентифіковані та описані наступними диференціальними рівняннями: при введенні розчину борної кислоти:

$$
T_{1} \cdot \frac{d C_{b o r}}{d \tau}+\Delta C_{b o r}=k_{1} \cdot \Delta G_{b o r}
$$

при введенні чистого конденсату:

$$
T_{2} \cdot \frac{d C_{b o r}}{d \tau}+\Delta C_{b o r}=k_{2} \cdot \Delta G_{H_{2} O}
$$

де $C_{b o r}-$ концентрація борної кислоти, г/кг;

$k_{1}, k_{2}$ - коефіцієнти передачі, $2 / \kappa 2 / \mathrm{m} / 2$ од;

$T_{1}, T_{2}$ - постійні часу, с;

$\Delta G_{b o r}$ - зміна витрати розчину борної кислоти, т/год;

$\Delta G_{H_{2} O}-$ зміна витрати чистого конденсату, т/год;

В рамках дослідження було прийнято, що номінальна витрата борної кислоти $\Delta G_{b o r}=40 \mathrm{~m} / 20 \partial$, номінальна витрата чистого конденсату $\Delta G_{H_{2} O}=40 \mathrm{~m} / 2$ од. [3]

Для таких витрат:

коефіцієнти передачі:

постійні часу:

$$
k_{1}=40^{2 / \kappa 2} / \mathrm{m} / 2 \text { од }, k_{2}=16^{2 / \kappa 2} / \mathrm{m} / 2 \text { од }
$$

$$
T_{1}=22318 c, T_{2}=47715 c .
$$

Для процесів введення і виведення бору з теплоносія коефіцієнти передачі відрізняються в 2,5 рази, а постійні часу - в 2 рази.

Для автоматизації підтримання необхідної концентрації БК необхідно синтезувати регулятор. Але об'єкт регулювання має різні статичні та динамічні характеристики при нанесенні керуючого впливу з різними знаками.

Таким чином виникає задача синтезу та дослідження системи регулювання концентрації борної кислоти в теплоносії першого контуру для нелінійного об'єкту регулювання.

Досліджу вальна частина

Для реалізації поставленої задачі розробили схему регулювання зміни концентрації борної кислоти в середовищі імітаційного моделювання Simulink пакета MATLAB (1-4 AE К761327 ВД, № 308918).Схема моделювання АСР наведена на рисунку 2. 


\section{МЕТОДИ ТА АЛГОРИТМИ ЕФЕКТИВНОГО УПРАВЛІННЯ ОБ‘ЭКТАМИ}

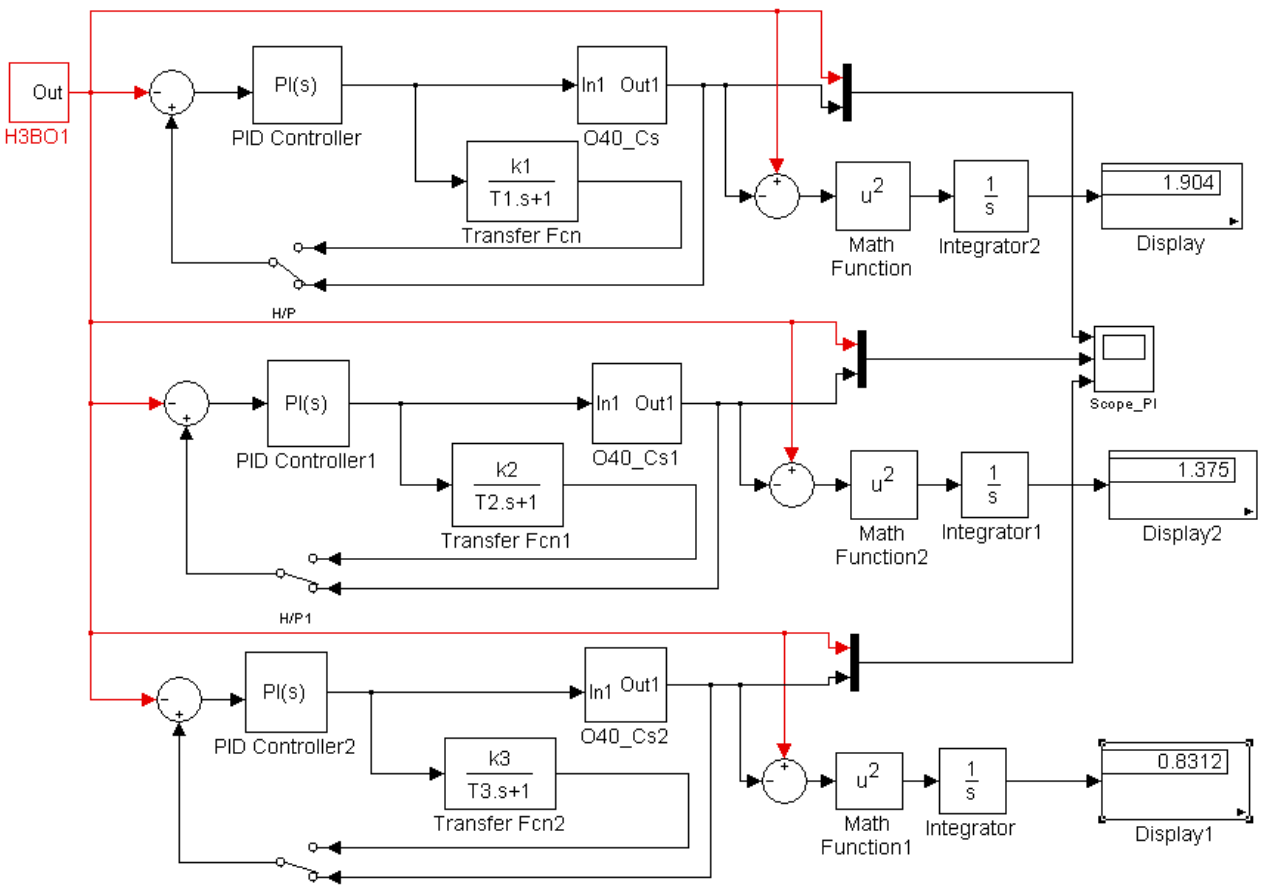

Рис. 2. Схема моделювання АСР концентрації борної кислоти

Для пошуку оптимальних налаштувань регулятора були розглянуті 3 варіанти динамічних властивостей об'єкта управління і для кожного з них були обчислені налаштування регуляторів для 3 типів перехідних процесів.

Об'єкти мали наступні характеристики:

$$
\begin{aligned}
& \text { 1) Об'єкт } 1: k_{\text {nep } 1}=40^{2 / \kappa 2} / \mathrm{m} / \text { год }, T_{1}=22318 c ; \\
& \text { 2) Об'єкт } 2: k_{\text {nep } 2}=28^{2 / \kappa 2} / \mathrm{m} / \text { год }, T_{2}=32500 \mathrm{c} ; \\
& \text { 2) Об'єкт } 3: k_{\text {nер } 3}=16^{2 / \kappa 2} / \mathrm{m} / \text { год }
\end{aligned}
$$

Були прийняті три типи перехідних процесів регулювання за такими показниками якості [4]:

- Аперіодичний процес ;

- Перехідний процес з 20\% перерегулюванням ;

- Перехідний процес з мінімальним часом регулювання.

Для порівняння якості перехідних процесів між собою був прийнятий інтегральний критерій якості :

$$
I=\int_{0}^{t_{\max }}(z-y)^{2} d t
$$

Спочатку досліджувалася АСР з ПІ регулятором.

Після розрахунків налаштувань ПІ регулятора ці значення були використані для моделювання АСР 3 нелінійною моделлю. Таким чином були отримані 9 перехідних процесів регулювання.

На основі аналізу отриманих процесів був зроблений висновок, що оптимальним можна вважати налаштування ПІ регулятора для процесу з найменшим часом регулювання. Графіки саме цих процесів наведені на рисунку 3. 


\section{МЕТОДИ ТА АЛГОРИТМИ ЕФЕКТИВНОГО УПРАВЛІННЯ ОБ‘ЭКТАМИ}
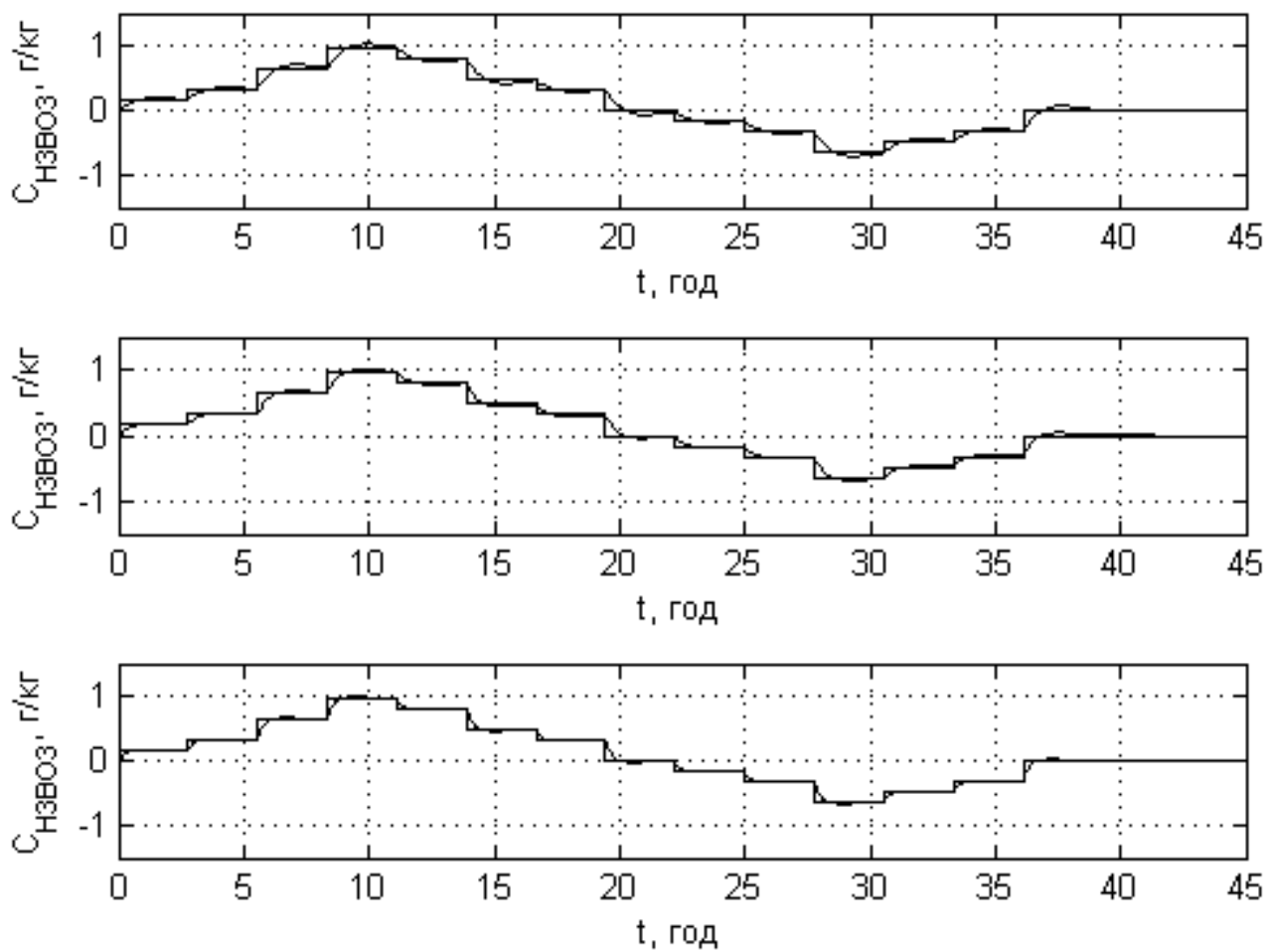

Рис. 3. Графік перехідного процесу регулювання з ПІ регулятором для об’єктів з різними динамічними властивостями

3 рисунку можна побачити, що мінімальне відхилення від сигналу завдання має перехідний процес для об'єкта номер 3. Згідно з таблицею 1 ,також цей процес має мінімальне значення інтегрального критерію якості $I_{3}=0.8312$. Тобто ПІ регулятор необхідно розраховувати для об'єкта з мінімальним коефіцієнтом передачі та максимальною постійною часу.

Таблиця 1 Значення інтегрального критерію якості для ПІ та ПІД регуляторів

\begin{tabular}{|c|c|c|}
\hline № & $\begin{array}{c}\text { ПІ } \\
\text { регулятор }\end{array}$ & $\begin{array}{c}\text { ПІД } \\
\text { регулятор }\end{array}$ \\
\hline 1. & 1.904 & 1.559 \\
\hline 2. & 1.375 & 3.09 \\
\hline 3. & 0.8312 & 2.074 \\
\hline
\end{tabular}

Далі було проведено дослідження АСР з ПІД регулятором.

Після розрахунків налаштувань ПІД регулятора ці значення також були використані для моделювання АСР 3 нелінійною моделлю. Таким чином також були отримані 9 перехідних процесів регулювання.

На основі аналізу отриманих процесів був зроблений висновок, що оптимальним можна вважати налаштування ПІД регулятора також на процес 3 найменшим часом регулювання. Графіки саме цих процесів наведені на рисунку 4. 


\section{МЕТОДИ ТА АЛГОРИТМИ ЕФЕКТИВНОГО УПРАВЛІННЯ ОБ`ЭКТАМИ}
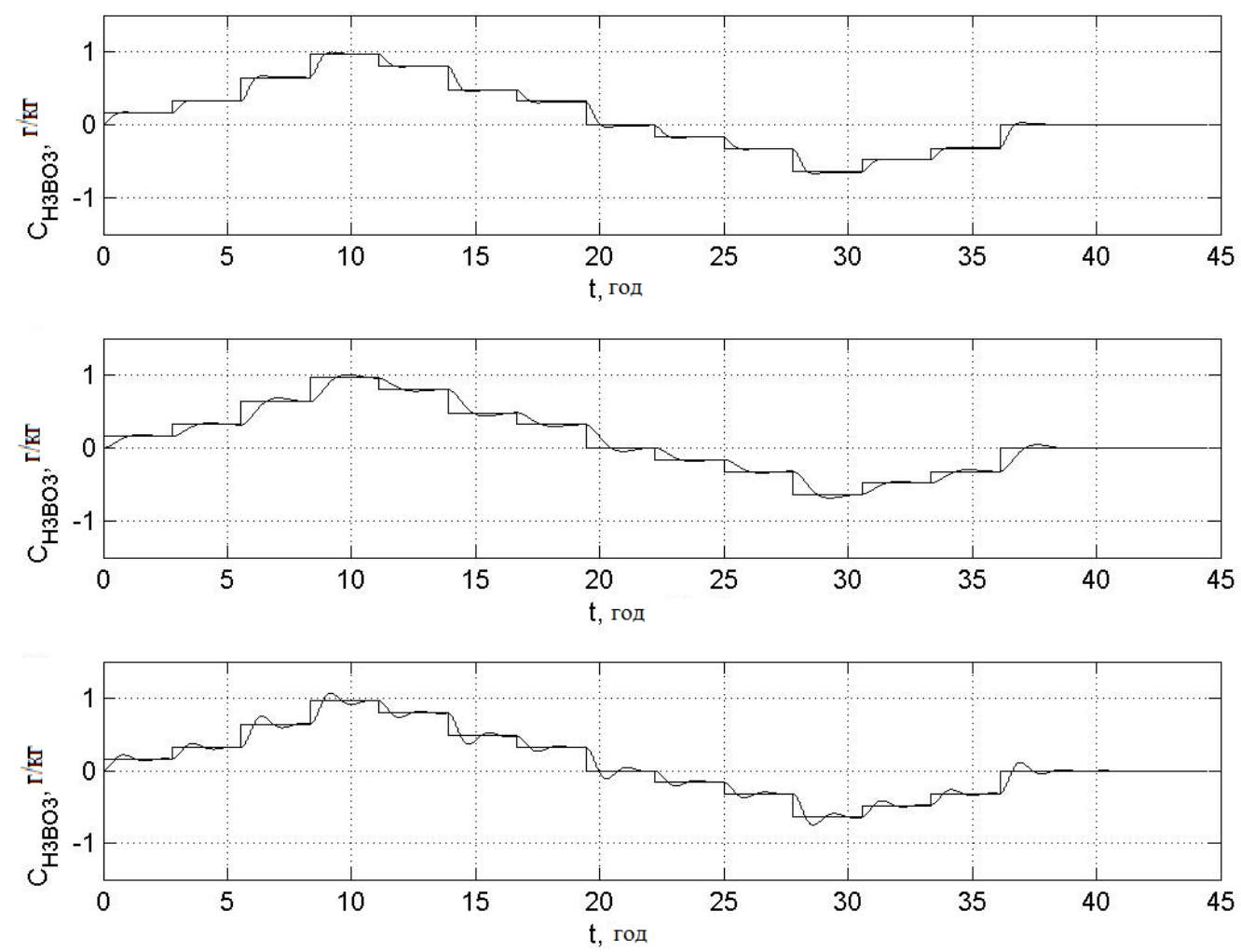

Рис. 4. Графік перехідного процесу регулювання з ПІД регулятором для об’єктів з різними динамічними властивостями

3 рисунку можна побачити, що мінімальне відхилення від сигналу завдання має перехідний процес для об’єкта номер 1. Тобто, на відміну від налаштувань ПІ регулятора, найкращий процес регулювання спостерігається для об’єкту з максимальним коефіцієнтом передачі та мінімальною постійною часу. Згідно 3 таблицею 1, також цей процес має мінімальне значення інтегрального критерію якості $I_{1}=1.559$.

\section{Висновок}

При регулювання концентрації борної кислоти в першому контурі енергоблоку АЕС об'єкт регулювання має різні властивості при нанесенні керуючого впливу різних знаків. Тому при налаштуванні регулятора на нелінійний об’єкт регулювання слід прийняти рішення про закон регулювання (ПІ або ПІД) та оптимальні налаштування регУлятора.

Для об'єкту розробленого в роботах [2] та [3] були синтезовані ПІ та ПІД регулятори. Порівнюючи графіки перехідних процесів з використанням ПІ регулятора, можна зробити висновок, що оптимальними можна вважати налаштування для об’єкта 3 мінімальним коефіцієнтом передачі та максимальною постійною часу. Так як для інших випадків спостерігається пере регулювання, що не бажано для експлуатації реактору.

Порівнюючи графіки перехідних процесів з використанням ПІД регулятора, можна зробити висновок, що оптимальними можна вважати налаштування для об’єкта 3 максимальним коефіцієнтом передачі та мінімальною постійною часу.

I на останок, якщо порівнювати ПІ та ПІД регулятор, то з точки зору інтегрального критерію якості оптимальним $\epsilon$ ПІ регулятор.

Проведені дослідження показують що оптимальним можна вважати використання ПІ регулятора, який налаштований на об’єкт з мінімальним коефіцієнтом передачі та максимальною постійною часу. 
Література

[1] Pelykh S.N. Cladding rupture life control methods for a power-cycling WWER-1000 nuclear unit/S.N. Pelykh, M.V. Maksimov // Nuclear Engineering and Design. — 2011. — Vol. 241, № 8. — P. 2956-2963;

[2] Maksimov, M. V. A model of a power unit with WWER-1000 as an object of power control [Text] / M. V. Maksimov, K. V. Beglov, T. A. Tsiselskaya // works of the Odessa Polytechnic University. — Odessa, 2012. — Rel. 1(38). — P. 104-106;

[3] Медведєв Р.Б., Сангінова О.В. Оптимальне керування процесом зміни концентрації борної кислоти в теплоносії першого контуру АEC 3 ВВEР-1000 // Наукові вісті Національного технічного університету України “Київський політехнічний інститут”. - 2002. - № 2 (22). - С. 22;

[4] Харабет О.М. Вивчення класичної теорії автоматичного управління за допомогою персонального комп'ютера /О.М.Харабет. - О.:Бахва,2014. -188c.

References

[1] Pelykh S.N. Cladding rupture life control methods for a power-cycling WWER-1000 nuclear unit/S.N. Pelykh, M.V. Maksimov // Nuclear Engineering and Design. - 2011. - Vol. 241, № 8. — P. 2956-2963;

[2] Maksimov, M. V. A model of a power unit with WWER-1000 as an object of power control [Text] / M. V. Maksimov, K. V. Beglov, T. A. Tsiselskaya // works of the Odessa Polytechnic University. — Odessa, 2012. - Rel. 1(38). - P. 104-106.;

[3] Medvedev R.B., Sanginova O. Optimal process control of change of concentration of boric acid in the coolant-moderator of the first to the contour of AES from WWER- $1000 / /$ the Scientific news of the National technical university of Ukraine the "Kyiv polytechnic institute". - 2002. - № 2 (22). - C. 22;

[4] Kharabet O.M. A study of classic theory of automatic control is by means of the personal computer /of O.M. Kharabet - O. of: Bakhva, 2014. -188.

\section{СИНТЕЗ И ИССЛЕДОВАНИЕ ЦИФРОВЫХ СИСТЕМ СУПЕРВИЗОРНОГО УПРАВЛЕНИЯ КОЛОННОЙ РЕКТИФИКАЦИИ НЕФТИ}

Design and research of digital supervisory control systems of a crude oil distillation column

Стопакевич А.А. ${ }^{1}$, Стопакевич А. A. ${ }^{2}$ (Stopakevych Andrii, Stopakevych Oleksii)

${ }^{1}$ Одесская национальная академия связи им. Попова, Одесса,

${ }^{2}$ Одесский национальный политехнический университет, Одесса

E-mail: stopakevich@gmail.com

Copyright (C) 2014 by author and the journal "Automation technological and business - processes".

This work is licensed under the Creative Commons Attribution International License (CC BY).

http://creativecommons.org/licenses/by/4.0/

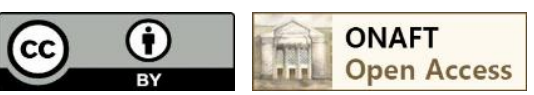

DOI: $10.15673 /$

Аннотация

В статье разрабатываются и исследуются новые системы управления нефтяной ректификационной колонной К-2 на основе нового применения супервизорного подхода. Показано, что такой подход снова распространяется в мировой практике автоматизации технологических процессов, особенно в нефтегазовой отрасли. В статье рассмотрены преимущества связки САУ на базе классических регуляторов ПИД- 